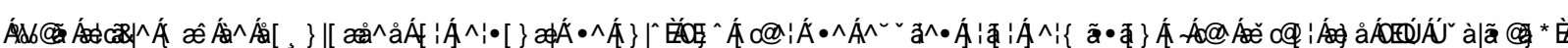

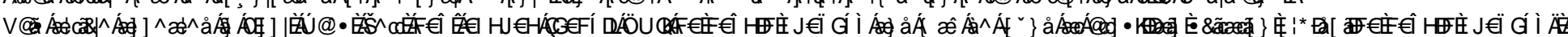

"This is the submitted version of the following article: U. Plaznik et al., Bulk relaxor ferroelectric ceramics as a working body for an electrocaloric cooling device, Applied Physics Letters, 106, 043903 (2015); doi: 10.1063/1.4907258 which has been published in final form at https://aip.scitation.org/doi/10.1063/1.4907258"

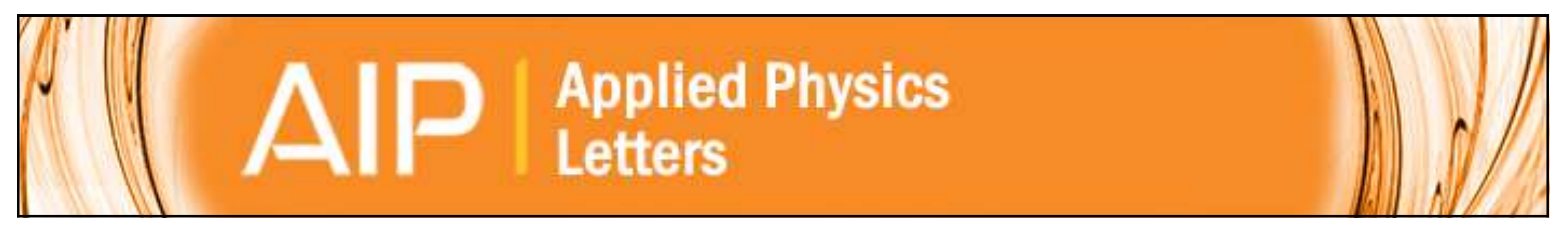

\section{Bulk relaxor ferroelectric ceramics as a working body for an electrocaloric cooling device}

Uroš Plaznik, Andrej Kitanovski, Brigita Rožič, Barbara Malič, Hana Uršič, Silvo Drnovšek, Jena Cilenšek, Marko Vrabelj, Alojz Poredoš, and Zdravko Kutnjak

Citation: Applied Physics Letters 106, 043903 (2015); doi: 10.1063/1.4907258

View online: http://dx.doi.org/10.1063/1.4907258

View Table of Contents: http://scitation.aip.org/content/aip/journal/apl/106/4?ver=pdfcov

Published by the AIP Publishing

\section{Articles you may be interested in}

Development of "fragility" in relaxor ferroelectrics

J. Appl. Phys. 115, 054106 (2014); 10.1063/1.4864256

Electrocaloric properties in relaxor ferroelectric $(1-\mathrm{x}) \mathrm{Pb}(\mathrm{Mg} 1 / 3 \mathrm{Nb} 2 / 3) \mathrm{O} 3-\mathrm{xPbTiO} 3$ system

J. Appl. Phys. 114, 174105 (2013); 10.1063/1.4829012

Electro-caloric effect in PLZT (8/65/35) ceramic

AIP Conf. Proc. 1447, 1281 (2012); 10.1063/1.4710480

Influence of the critical point on the electrocaloric response of relaxor ferroelectrics

J. Appl. Phys. 110, 064118 (2011); 10.1063/1.3641975

Organic and inorganic relaxor ferroelectrics with giant electrocaloric effect

Appl. Phys. Lett. 97, 162904 (2010); 10.1063/1.3501975

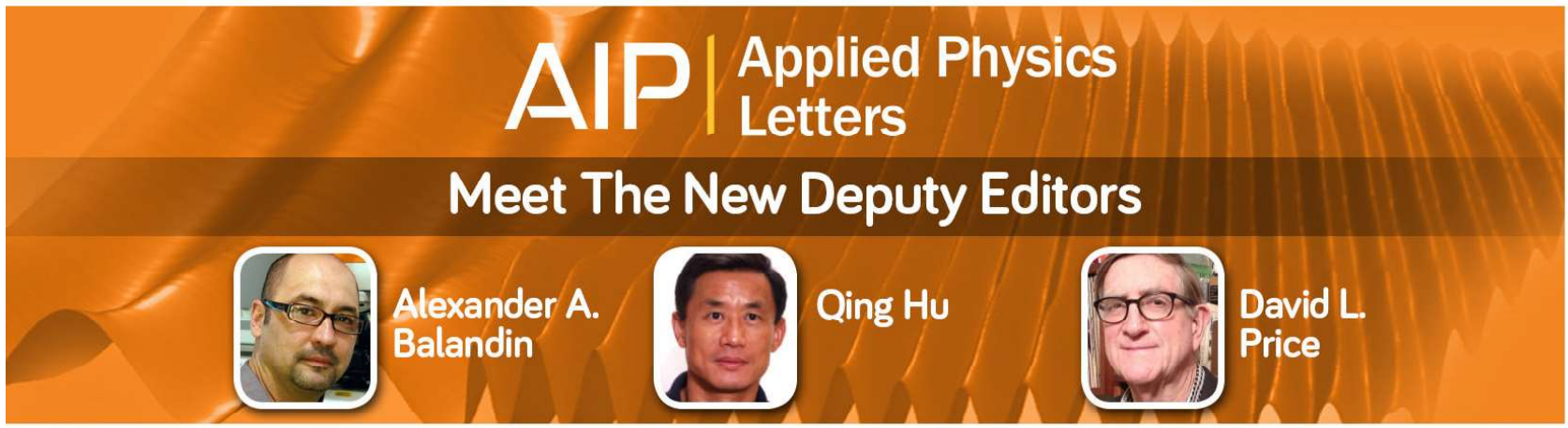




\title{
Bulk relaxor ferroelectric ceramics as a working body for an electrocaloric cooling device
}

\author{
Uroš Plaznik, ${ }^{1}$ Andrej Kitanovski, ${ }^{1}$ Brigita Rožič, ${ }^{2}$ Barbara Malič, ${ }^{2,3}$ Hana Uršič, ${ }^{2}$ \\ Silvo Drnovšek, ${ }^{2}$ Jena Cilenšek, ${ }^{2}$ Marko Vrabelj, ${ }^{2,3}$ Alojz Poredoš, ${ }^{1}$ \\ and Zdravko Kutnjak ${ }^{2,3, a)}$ \\ ${ }^{1}$ University of Ljubljana, Faculty of Mechanical Engineering, Aškerčeva 6, 1000 Ljubljana, Slovenia \\ ${ }^{2}$ Jožef Stefan Institute, P.O. Box 3000, 1001 Ljubljana, Slovenia \\ ${ }^{3}$ Jožef Stefan International Postgraduate School, Jamova 39, 1000 Ljubljana, Slovenia
}

(Received 8 December 2014; accepted 21 January 2015; published online 30 January 2015)

\begin{abstract}
The electrocaloric effect (ECE), i.e., the conversion of the electric into the thermal energy has recently become of great importance for development of a new generation of cooling technologies. Here, we explore utilization of $\left[\mathrm{Pb}\left(\mathrm{Mg}_{1 / 3} \mathrm{Nb}_{2 / 3}\right) \mathrm{O}_{3}\right]_{0.9}\left[\mathrm{PbTiO}_{3}\right]_{0.1}$ ( $\left.\mathrm{PMN}-10 \mathrm{PT}\right)$ relaxor ceramics as active elements of the heat regenerator in an ECE cooling device. We show that the PMN-10PT relaxor ceramic exhibits a relatively large electrocaloric change of temperature $\Delta T_{E C}>1 \mathrm{~K}$ at room temperature. The experimental testing of the cooling device demonstrates the efficient regeneration and establishment of the temperature span between the hot and the cold sides of the regenerator, exceeding several times the $\Delta T_{E C}$ within a single PMN-10PT ceramic plate. (C) 2015 AIP Publishing LLC.

[http://dx.doi.org/10.1063/1.4907258]
\end{abstract}

The electrocaloric effect (ECE) is the dipolar entropy and consequently temperature change when an electric field is applied to a polar material under adiabatic conditions. ${ }^{1}$ Very recently, a revival of ECE was induced by the discovery of a large electrocaloric effect in some organic and inorganic ferroelectric materials such as thin PZT films ${ }^{2}$ and in thick P(VDFTrFE) polymer films. ${ }^{2-9}$ Electrocaloric cooling is a rather new and promising alternative cooling technology, ${ }^{10}$ which may provide an effective mean to realize solid-state cooling for a broad range of applications including temperature regulation and on-chip cooling. Refrigeration based on the ECE may provide an alternative to the existing vapor-compression approach and could have an advantage over solid-state thermoelectric-cooling devices, because of strong insulating properties of dielectric materials and consequently a negligible Joule heating. Though analogous to the magnetocaloric cooling, electrocaloric cooling exhibits some potential advantages. The most important ones include: higher power densities, compactness, smaller mass of a device, potential cost reduction, no dependence on rare-earth materials, etc. ${ }^{11}$

Currently, the most promising electrocaloric materials are found among relaxor ferroelectric ceramics ${ }^{4,6,12}$ and polymers. ${ }^{3,13,14}$ Typically, ceramics would better sustain higher electric fields than single crystals. Based on their thickness, ceramic materials are further divided between bulk ceramics (thickness $>100 \mu \mathrm{m}$ ), thick films (thickness of a few $10 \mu \mathrm{m}$ ), and thin films (thickness $<1 \mu \mathrm{m}$ ). The ECE of bulk ceramics and thick films is usually below $4 \mathrm{~K}^{12,15-17}$ On the other hand, the ECE of thin films can be in some cases as high as $40 \mathrm{~K} .{ }^{14,18}$ Electrocaloric polymer materials are mostly in the form of thin and thick films, with their thicknesses between 1 and $10 \mu \mathrm{m}$. Similar to ceramic thin films, the ECE of some polymer films can reach up to a few tens of $\mathrm{K}^{3,13,14}$ However, thin-film ceramic and polymer

${ }^{a)}$ zdravko.kutnjak@ijs.si materials which can achieve such high ECE need to be further processed to multilayer structures before they could be implemented into a cooling device. ${ }^{19}$ Such technology is not yet fully commercially available. On the other hand, bulk ceramic materials even with a relatively modest ECE could already be implemented in a cooling device by exploiting a so-called heat regeneration process. Different concepts of such systems have already been proposed in electrocaloric refrigeration; ${ }^{10,19-23}$ however, only a few have been experimentally validated. ${ }^{19,21}$ A possible solution is to design a device with an active electrocaloric regenerator (AER). Such solution was first introduced in the field of electrocaloric refrigeration and experimentally tested by Sinyavsky and Brodyansky. ${ }^{21}$ Recently, different authors ${ }^{11,24}$ theoretically evaluated the performance of an electrocaloric cooling device with an AER and showed that it could surpass the performance of some other alternative cooling technologies.

In this letter, we provide the test of electrocaloric properties of the $\left[\mathrm{Pb}\left(\mathrm{Mg}_{1 / 3} \mathrm{Nb}_{2 / 3}\right) \mathrm{O}_{3}\right]_{0.9}\left[\mathrm{PbTiO}_{3}\right]_{0.1}$ (PMN-10PT) relaxor ferroelectric ceramic along with the test of its utilization as the active elements of the heat regenerator in a small scale electrocaloric cooling device.

For the synthesis of the PMN-10PT ceramic powder, $\mathrm{PbO}$ (99.9\%, Aldrich), $\mathrm{MgO}$ (98\%, Aldrich), $\mathrm{TiO}_{2}$ (99.8\%, Alfa Aesar), and $\mathrm{Nb}_{2} \mathrm{O}_{5}(99.9 \%$, Aldrich) were used. A mixture of these oxides in the molar ratio corresponding to the stoichiometry of PMN-10PT was homogenized and then high-energy milled in a planetary mill (Retsch, Model PM 400 ) at $300 \mathrm{rpm}$ for $96 \mathrm{~h}$. Afterwards, the powder was milled in an attritor mill at $800 \mathrm{rpm}$ for $4 \mathrm{~h}$ in isopropanol and dried. The powder compacts were pressed uniaxially at $50 \mathrm{MPa}$ and then isostatically at $300 \mathrm{MPa}$ and sintered in double alumina crucibles in the presence of the PMN-10PT packing powder at $1200^{\circ} \mathrm{C}$ for $2 \mathrm{~h}$. Heating and cooling rates were $2^{\circ} \mathrm{C} / \mathrm{min}$. For electrocaloric measurements, ceramic plates were cut to $10 \times 20 \mathrm{~mm}^{2}$, polished to $200 \mu \mathrm{m}$, annealed at $600^{\circ} \mathrm{C}$ for $1 \mathrm{~h}$, 
and cooled with the rate of $1^{\circ} \mathrm{C} / \mathrm{min}$. Afterwards, the $\mathrm{Cr} / \mathrm{Au}$ electrodes were deposited on both faces by RF-sputtering. Using such approach, 30 identical plates were prepared to be used in the AER.

Before using PMN-10PT plates in the AER, the electrocaloric response was measured by a direct method described in Refs. 15 and 25. Here, the electrocaloric response was studied by using a high resolution calorimeter, ${ }^{1,26}$ which allows precise temperature stabilization (within $0.1 \mathrm{mK}$ ) and high-resolution measurements of the sample temperature variation. Results of the measured ECE response in PMN10PT bulk ceramics are shown in Figure 1. The temperature dependence of the ECE temperature change $\Delta T_{E C}$ was measured at different amplitudes of the electric field in the temperature interval between $300 \mathrm{~K}$ and $415 \mathrm{~K}$. The largest ECE amplitude $\Delta T_{E C}$ was obtained near the induced ferroelectric transition. ${ }^{15,16}$ At room temperature, the ECE response was typically from 0.6 to $1.5 \mathrm{~K}$ for moderate field changes from 28 to $115 \mathrm{kV} / \mathrm{cm}$, respectively. As shown in Figure 1, the indirectly obtained data agree well with the directly measured EC response.

The active electrocaloric regenerator can be, in general, described as a porous structure of an electrocaloric material and voids through which a fluid can flow. In order to apply the electrocaloric material of the AER to a thermodynamic cycle, the AER should be implemented in a system that comprises a heat sink, a heat source, a fluid pumping system, an electric field generator, and a housing. A schematic presentation of such a system and its four main working steps are presented in Figure 2. In the first step (see Figure 2(a)), the electrocaloric material is polarized and due to the ECE the material heats up. Then, the fluid flows from the heat source to the heat sink (the first period of the fluid flow) and heat is transferred from the electrocaloric material to the fluid. When the fluid exits the AER, it enters the hot heat exchanger where heat is transferred from the fluid to the heat

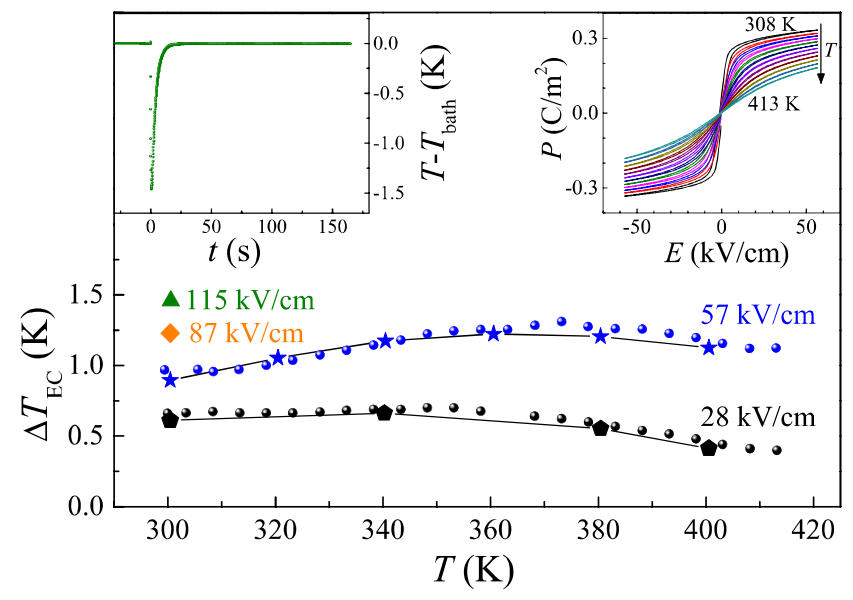

FIG. 1. ECE response of PMN-10PT ceramics. Temperature variation of the ECE temperature change $\Delta T_{E C}$ for different amplitudes of electric-field pulses. The solid circles represent the indirect EC data obtained from the polarization-electric field hysteresis loops shown in the right inset. The polarization-electric field hysteresis loops were measured with the Aixacct TF analyser 2000 at $1 \mathrm{~Hz}$. The other symbols represent the directly measured $\mathrm{EC}$ data as shown in the left inset for the EC response obtained during the field removal. (a)

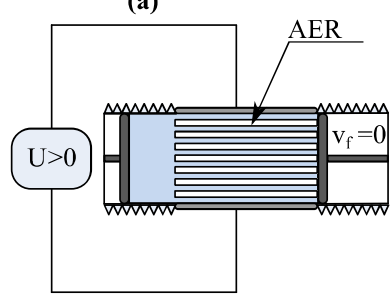

(c)

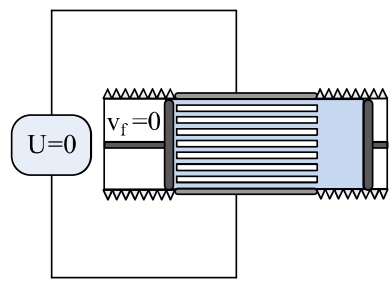

FIG. 2. Schematic presentation of the four main working steps of a system with an AER. $U$ stands for the voltage, $v_{f}$ stands for the fluid flow velocity, HSI stands for the heat sink, HSO stands for the heat source, HHX stands for the hot heat exchanger, $\mathrm{CHX}$ stands for the cold heat exchanger, and the transferred heat is denoted by $\mathrm{Q}$.

sink (see Figure 2(b)). Next, the electrocaloric material is depolarized and its temperature decreases (see Figure 2(c)). The fluid, this time flowing in the counter direction as in the second step, cools down (the second period of the fluid flow). By exiting the AER and entering the cold heat exchanger, the fluid absorbs the heat from the heat source (see Figure 2(d)). These steps are repeated and the steady state (in which the temperature span of the device does not change any more) is reached after a certain time. In the scenario described above, the electrocaloric material is subjected to the Brayton thermodynamic cycle. However, the electrocaloric material could be subjected to other, potentially more efficient thermodynamic cycles, such as the Ericsson or the hybrid Brayton-Ericsson cycle. ${ }^{27,28}$

According to the general description of a cooling system with an AER, a small scale device was designed. A schematic presentation of the AER device cross-section is shown in Figure 3(a). The AER was constructed from three stacks. Each stack was assembled from 10 bulk PMN-10PT ceramic plates with the geometry as described above. The ceramic plates were put on top of each other with spacers of the thickness of $100 \mu \mathrm{m}$ inserted between them to create voids for the fluid flow. Every second spacer was made of stainless steel in order to create the electrical contact between the electrodes of ceramics plates and the electric field generator. Each stack had the length of $20 \mathrm{~mm}$, thereby creating the AER with the total length of $60 \mathrm{~mm}$. On both sides of the AER (hot and cold side), thermocouples were attached to measure the fluid temperature during the device operation. The housing was filled with the dielectric silicon oil and a small tube was used to connect the housing to a bidirectional peristaltic pump (Figure 3(b)).

In order to ensure that the device was working under the Brayton cycle, the device was connected to a controlling system, which regulated the function of the peristaltic pump and the electric field generator. One of the controlling parameters of the device that can be regulated is a dimensionless number $V^{*}$. It is defined as the amount of the fluid pumped through 
(a)

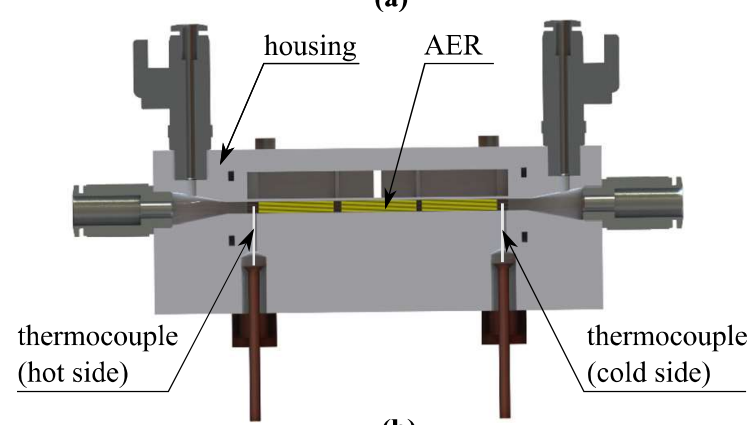

(b)

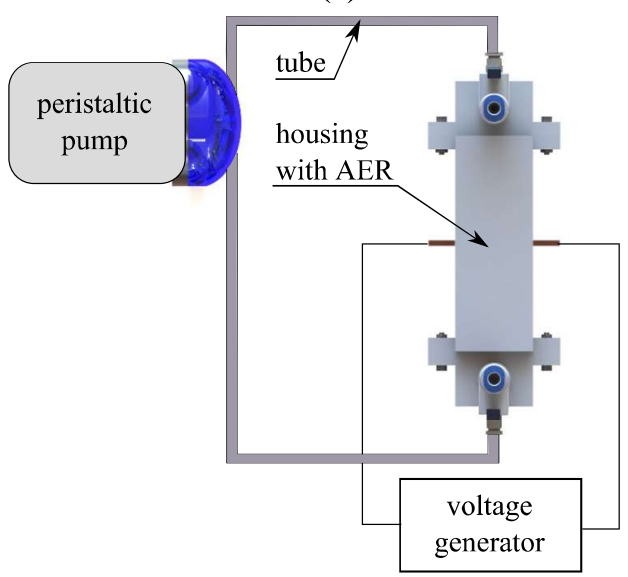

FIG. 3. (a) A cross-section of the AER-housing with the PMN-10PT stacks labelled by AER. (b) Schematic presentation of the small-scale cooling system.

the AER in one period of the fluid flow over the total amount of the fluid contained in the AER.

Two sets of measurements were performed at two different magnitudes of the electric field, i.e., 25 and $50 \mathrm{kV} / \mathrm{cm}$. The temperature span across the device was measured for different $V^{*}$ (see Figure 4(a)) at each value of the electric field. For both sets of measurements, the number of thermodynamic cycles per unit of time, i.e., the operating frequency was $0.75 \mathrm{~Hz}$. As expected, larger temperature spans were obtained at larger electric field changes. As shown in Figure 4(a), for both magnitudes of the electric field, an optimum value of $V^{*}$ exists at which the established temperature span is the largest. The maximum temperature spans of $2.3 \mathrm{~K}$ and $3.3 \mathrm{~K}$ were established for 25 and $50 \mathrm{kV} / \mathrm{cm}$, respectively.

The regeneration factor defined as the ratio between the temperature span established across the device and the $\Delta T_{E C}$ of the electrocaloric material at the same electric field change is presented in Figure 4(b). The regeneration factor is less dependent on the electric field change; however, it shows strong dependence on the ratio $V^{*}$. For both electric field amplitudes, a maximum regeneration factor of approximately 3.7 was achieved. This regeneration factor exceeds so far published regeneration factors for almost factor of two. ${ }^{20}$

In order to evaluate the performance of the device with a longer AER and with deionized purified water as the working fluid instead of the dielectric silicon oil, a simulation based on a 2D dynamic numerical model was carried out. Similar models $\mathrm{s}^{29,30}$ were used to investigate the performance of the active magnetic regenerator, which is, from the heat transfer point of view, analogous to the AER. The ECE was (a)

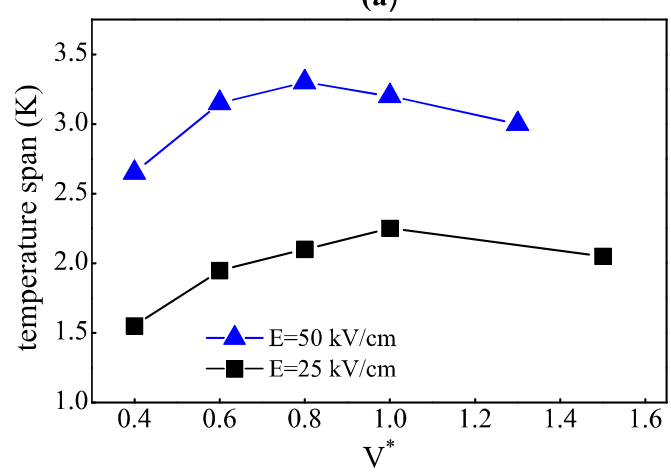

(b)

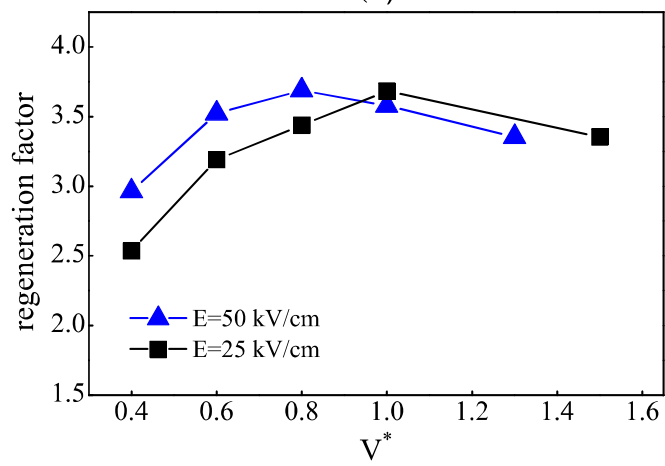

FIG. 4. (a) Temperature span as a function of $V^{*}$ for two different amplitudes of the electric field. (b) Regeneration factor as a function of $V^{*}$ for two different amplitudes of the electric field.

implemented in the model by the so called direct application, ${ }^{29}$ using measured $\Delta T_{E C}$ (Figure 1), what enabled us to investigate the performance of the device at higher electric fields than those applied in the experiment. Furthermore, the time length of the first and the second period of the fluid flow (Figure 2) can be varied in the model, enabling us to simulate the performance of the device at various frequencies. To account for different losses, an apparent heat generation, at which the results of the simulation matched the results of the experiment, was added to the heat source. The simulations shown in Figure 5 were performed for the same operating conditions as the experiment, but for a wider range

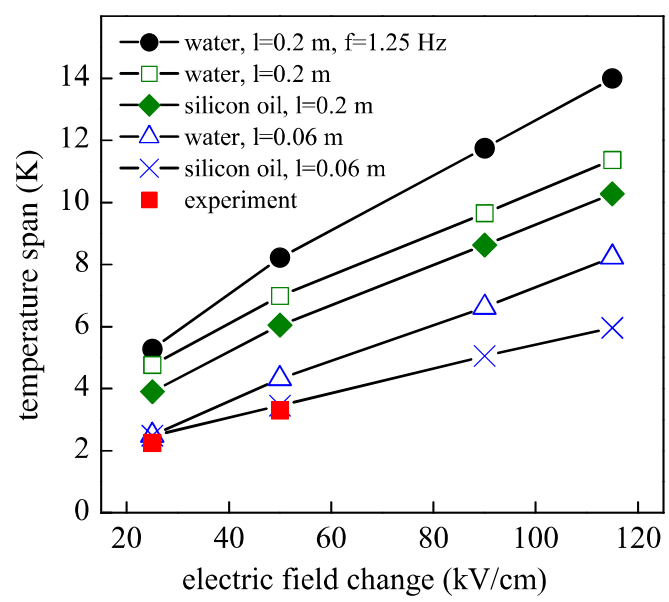

FIG. 5. The maximum temperature span of the device as a function of the electric filed change evaluated at various conditions. 
of electric field changes and operating frequencies. The results clearly show that the best temperature span of $14 \mathrm{~K}$ and regeneration factor of 9.6 were obtained under the electric filed change of $118 \mathrm{kV} / \mathrm{cm}$, by choosing the water as the working fluid, extending the regenerator length to $0.2 \mathrm{~m}$, and at the operating frequency of $1.25 \mathrm{~Hz}$, which was found to be the optimal operating frequency for the given geometry of the cooling device.

The above experiments and simulations demonstrate efficient regeneration and establishment of the temperature span between the hot and the cold sides of the regenerator reaching almost 10 times the $\Delta T_{E C}$ within a single PMN$10 \mathrm{PT}$ ceramic plate. It is also expected that by optimizing other properties of the AER, such as plate thickness and fluid flow channel height, the performance of the device could be further improved, thus making PMN-10PT bulk ceramic with the increased applied electric field a potential candidate for the AER active material in an alternative dielectric cooling technology.

This work is dedicated to late Professor Marija Kosec. This work was supported by the Slovenian Research Agency through Grant Nos. L2-6768, P2-0105, P1-0125, and J2-6779-1.

${ }^{1}$ T. Correia and Q. Zhang, Electrocaloric Materials (Springer-Verlag, Berlin, Heidelberg, 2014).

${ }^{2}$ A. S. Mischenko, Q. Zhang, J. F. Scott, R. W. Whatmore, and N. D. Mathur, Science 311, 1270 (2006).

${ }^{3}$ B. Neese, B. Chu, S. G. Lu, Y. Wang, E. Furman, and Q. M. Zhang, Science 321, 821 (2008).

${ }^{4}$ A. S. Mischenko, Q. Zhang, R. W. Whatmore, J. F. Scott, and N. D. Mathur, Appl. Phys. Lett. 89, 242912 (2006).

${ }^{5}$ G. Akcay, S. P. Alpay, G. A. Rossetti, and J. F. Scott, J. Appl. Phys. 103, 024104 (2008).

${ }^{6}$ D. Guyomar, G. Sebald, B. Guiffard, and L. Seveyrat, J. Phys. D: Appl. Phys. 39, 4491 (2006)

${ }^{7}$ S. Prosandeev, I. Ponomareva, and L. Bellaiche, Phys. Rev. B 78, 052103 (2008).
${ }^{8}$ S. Kar-Narayan and N. D. Mathur, J. Phys. D: Appl. Phys. 43, 032002 (2010).

${ }^{9}$ G. Akcay, S. P. Alpay, M. V. Maltese, and G. A. Rossetti, Appl. Phys. Lett. 90, 252909 (2007).

${ }^{10}$ M. Ožbolt, A. Kitanovski, J. Tušek, and A. Poredoš, Int. J. Refrig. 40, 174 (2014).

${ }^{11}$ M. Ožbolt, A. Kitanovski, J. Tušek, and A. Poredoš, Int. J. Refrig. 37, 16 (2014).

${ }^{12}$ G. Sebald, S. Pruvost, L. Seveyrat, L. Lebrun, D. Guyomar, and B. Guiffard, J. Eur. Ceram. Soc. 27, 4021 (2007).

${ }^{13}$ S. G. Lu, B. Rožič, Q. M. Zhang, Z. Kutnjak, X. Li, R. Pirc, L. J. Gorny, and M. Lin, Appl. Phys. Lett. 97, 202901 (2010).

${ }^{14}$ S. G. Lu, B. Rožič, Q. M. Zhang, Z. Kutnjak, X. Li, E. Furman, L. J. Gorny, M. Lin, B. Malič, M. Kosec, R. Blinc, and R. Pirc, Appl. Phys. Lett. 97, 162904 (2010)

${ }^{15}$ B. Rožič, M. Kosec, H. Uršič, J. Holc, B. Malič, Q. M. Zhang, R. Blinc, R. Pirc, and Z. Kutnjak, J. Appl. Phys. 110, 064118 (2011).

${ }^{16}$ J. Peräntie, H. N. Tailor, J. Hagberg, H. Jantunen, and Z.-G. Ye, J. Appl. Phys. 114, 174105 (2013).

${ }^{17}$ M. Valant, L. J. Dunne, A.-K. Axelsson, Neil McN. Alford, G. Manos, J. Peräntie, J. Hagberg, H. Jantunen, and A. Dabkowski, Phys. Rev. B 81, 214110 (2010).

${ }^{18}$ B. Peng, H. Fan, and Q. Zhang, Adv. Funct. Mater. 23, 2987 (2013).

${ }^{19}$ H. Gu, X. Qian, X. Li, B. Craven, W. Zhu, A. Cheng, S. C. Yao, and Q. M. Zhang, Appl. Phys. Lett. 102, 122904 (2013).

${ }^{20}$ H. Gu, X. S. Qian, H. J. Ye, and Q. M. Zhang, Appl. Phys. Lett. 105, 162905 (2014).

${ }^{21}$ Y. V. Sinyavsky and V. M. Brodyansky, Ferroelectrics 131, 321 (1992).

${ }^{22}$ S. F. Karmanenko, O. V. Pakhomov, A. M. Prudan, A. S. Starkov, and A. Eskov, J. Eur. Ceram. Soc. 27, 3109 (2007).

${ }^{23}$ R. I. Epstein and K. J. Malloy, J. Appl. Phys. 106, 064509 (2009).

${ }^{24}$ D. Guo, J. Gao, Y.-J. Yu, S. Santhanam, A. Slippey, G. K. Fedder, A. J. H. McGaughey, and S.-C. Yao, Int. J. Heat Mass Transfer 72, 559 (2014).

${ }^{25}$ B. Rožič, B. Malič, H. Uršič, J. Holc, M. Kosec, B. Neese, Q. M. Zhang, and Z. Kutnjak, Ferroelectrics 405, 26 (2010).

${ }^{26}$ Z. Kutnjak, J. Petzelt, and R. Blinc, Nature 441, 956 (2006).

${ }^{27}$ A. Kitanovski, U. Plaznik, J. Tušek, and A. Poredoš, Int. J. Refrig. 37, 28 (2014).

${ }^{28}$ U. Plaznik, J. Tušek, A. Kitanovski, and A. Poredoš, Appl. Therm. Eng. 59, 52 (2013).

${ }^{29}$ K. K. Nielsen, J. Tušek, K. Engelbrecht, S. Schopfer, A. Kitanovski, C. R. H. Bahl, A. Smith, N. Pryds, and A. Poredoš, Int. J. Refrig. 34, 603 (2011).

${ }^{30}$ P. A. Oliveira, P. V. Trevizoli, J. R. Barbosa, Jr., and A. T. Prata, Int. J. Refrig. 35, 98 (2012). 